\title{
Unifying activity, structure and spectroscopy of
}

\section{[NiFe] hydrogenases: combining techniques to}

\section{clarify mechanistic understanding}

\author{
Philip A. Ash ${ }^{1,2}{ }^{*}$ Sophie E. T. Kendall-Price, ${ }^{1}$ Kylie A. Vincent ${ }^{1}$ *
}

1. Department of Chemistry, University of Oxford, Oxford OX13QR, U.K.

2. School of Chemistry, University of Leicester, University Road, Leicester LE1 7RH, U.K.

*philip.ash@leicester.ac.uk; kylie.vincent@chem.ox.ac.uk

\section{Conspectus}
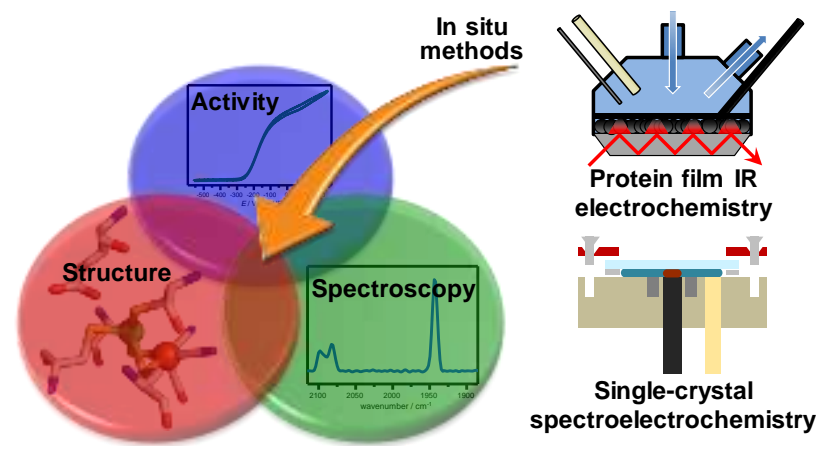

Achieving a unified understanding of the mechanism of a multi-center redox enzyme such as [NiFe] hydrogenase is complicated by difficulties in reconciling information obtained using different techniques, and on samples in different physical forms. Measurements of the activity of the enzyme, and of factors which perturb activity, are generally carried out using biochemical 
assays in solution or with electrode-immobilized enzyme using protein film electrochemistry (PFE). Conversely, spectroscopy aimed at reporting on features of the metalloclusters in the enzyme, such as electron paramagnetic resonance (EPR) or X-ray absorption spectroscopy (XAS), is often conducted on frozen samples and is thus difficult to relate to catalytically relevant states as information about turnover and activity has been lost. To complicate matters further, most of our knowledge of the atomic-level structure of metalloenzymes comes from Xray diffraction studies in the solid, crystalline state, which are again difficult to link to turnover conditions. Taking $[\mathrm{NiFe}]$ hydrogenases as our case study, we show here how it is possible to apply infrared (IR) spectroscopic sampling approaches to unite direct spectroscopic study with catalytic turnover. Using a method we have named protein film IR electrochemistry (PFIRE) we reveal the steady-state distribution of intermediates during catalysis, and identify catalytic 'bottlenecks' introduced by site-directed mutagenesis. We also show that it is possible to study dynamic transitions between active site states of enzymes in single crystals, uniting solid state and solution spectroscopic information. In all of these cases the spectroscopic data complement and enhance interpretation of purely activity-based measurements by providing direct chemical insight that is otherwise hidden. The $[\mathrm{NiFe}]$ hydrogenases possess a bimetallic $[\mathrm{NiFe}]$ active site, coordinated by $\mathrm{CO}$ and $\mathrm{CN}^{-}$ligands, linked to the protein via bridging and terminal cysteine sulfur ligands, as well as an electron relay chain of iron sulfur clusters. Infrared spectroscopy is ideal for probing hydrogenases because the $\mathrm{CO}$ and $\mathrm{CN}^{-}$ligands are strong IR absorbers, but the suite of IR-based approaches we describe here will be equally valuable in studying substrate- or intermediate-bound states of other metalloenzymes where key mechanistic questions remain open, such as nitrogenase, formate dehydrogenase or carbon monoxide dehydrogenase. We 
therefore hope that this article will encourage future studies which unify information from different techniques across bio-inorganic chemistry.

\section{Introduction}

In order to gain more complete understanding of complex redox metalloenzyme mechanisms, kinetic information, such as turnover frequencies and inhibition, must be considered alongside structural and spectroscopic data. These data are generally obtained by handling the enzyme in disparate ways; turnover studies in solution, spectroscopic measurements often on frozen samples, and structural measurements in the crystalline state. Relatively few techniques can probe or control activity simultaneously with a structural or spectroscopic measurement, and so it can be difficult to link kinetic information to spectroscopic observations. This is largely due to challenges in controlling turnover during sample preparation: incubation with substrate, in the absence of redox control, is a poor proxy for 'turnover'. The challenge is to develop methods that combine simultaneous activity measurement with structural and spectroscopic mechanistic insight.

Activity-based approaches which address factors affecting turnover frequency include biochemical assays, where redox dyes report indirectly on the rate of substrate oxidation or reduction, ${ }^{1}$ and direct electrochemical methods in which current response at an electrode reports on catalytic rate. ${ }^{2-4}$ Artificially-controlled enzyme activity, using small redox molecules, can be combined with stopped-flow or freeze-quench methods in an attempt to 'catch' transient catalytic states. Experimental dead-times are limiting, however, compared to high turnover frequencies of metalloenzymes such as hydrogenases or carbon monoxide dehydrogenase $\left(>1000 \mathrm{~s}^{-1}\right)$. Micromixing devices lower dead-times to microseconds, at the expense of large sample volumes. ${ }^{5-7}$ Pump-probe experiments offer valuable insight if catalysis can be initiated by light (without 
triggering unwanted photochemical side reactions). ${ }^{8-10}$ Direct electrochemical methods attempt to mimic the biological situation in which enzymes may be in direct electronic contact with another redox module, or a membrane redox pool which drives catalysis. ${ }^{11}$

Here, we discuss methods we have established to bridge the gaps between activity-based measurements, solution spectroscopic measurements, and measurements on proteins in the crystalline state, focusing on [NiFe] hydrogenases. We apply infrared (IR) spectroscopy which is particularly versatile in terms of sample handling. ${ }^{12}$ Use of high-brightness synchrotron and laser sources allows microspectroscopic IR sampling, lowers the amount of protein required, and enables high signal-to-noise kinetic studies. ${ }^{13-15}$

\section{[NiFe] hydrogenase structure and mechanism}

Hydrogenases remain a source of great curiosity to chemists and biochemists alike: their bimetallic catalytic core is similar to many small molecule metal carbonyl complexes known to inorganic chemists for several decades, but they possess catalytic rates that far exceed any known small molecule metal carbonyl systems. ${ }^{16,17}$ In fact, hydrogenases rival catalytic $\mathrm{H}_{2}$ oxidation rates at platinum active sites, far exceed platinum in selectivity for $\mathrm{H}_{2}$ over other small molecules that poison noble metals $\left(\mathrm{CO}, \mathrm{H}_{2} \mathrm{~S}\right.$, etc.), and in some cases favor $\mathrm{H}_{2}$ oxidation over redox chemistry of $\mathrm{O}_{2}$. [NiFe] hydrogenases possess native $\mathrm{CO}$ and $\mathrm{CN}^{-}$ligands coordinated to the iron atom of their catalytic site (Figure 1). ${ }^{18,19}$ These ligands function as excellent IR absorbers and reporters of electronic and coordination changes at the active site. Hydrogenases are equipped with a chain of iron sulfur clusters (Figure 1A) which link the [NiFe] active site electronically with the surface of the protein, allowing fast electron transfer to sustain catalysis. 

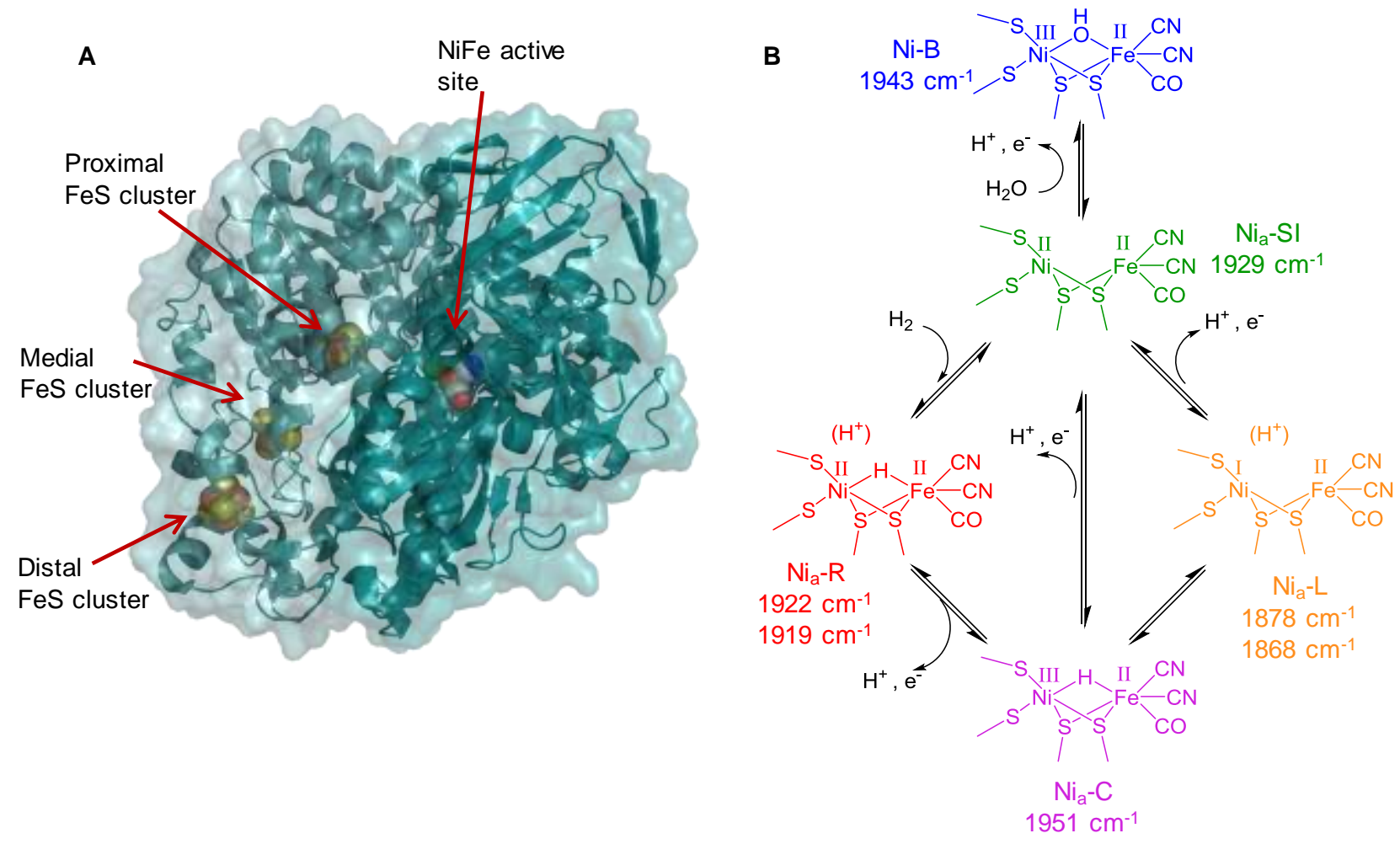

Figure 1. Structure and currently accepted catalytic cycle for [NiFe] hydrogenases. (A) Structure of [NiFe] hydrogenase I from E. coli, PDB 3UQY, prepared using Pymol ${ }^{20}$. (B) Catalytic cycle: states are color-coded to match IR spectra shown later, $v_{\mathrm{CO}}$ band positions refer to Hyd1, $\mathrm{pH}$ $6.0 .^{21}$

The catalytic cycle of [NiFe] hydrogenases comprises a series of linked electron and proton transfer steps (Figure 1B). The active site Fe atom remains formally Fe(II) throughout, although there is substantial delocalization as indicated by changes in $\mathrm{CO}$ and $\mathrm{CN}^{-}$wavenumber positions ( $v_{\mathrm{CO}}$ and $v_{\mathrm{CN}}$ ) in IR spectra, highly sensitive to electron density on Fe. ${ }^{22}$ The $v_{\mathrm{CO}}$ band positions of the active site of E. coli hydrogenase I (Hyd1) are given in Figure 1B. ${ }^{21,22}$ Starting at the Ni(II) level in the $\mathrm{Ni}_{2}-\mathrm{SI}$ state, and considered in the direction of $\mathrm{H}_{2}$ oxidation, $\mathrm{H}_{2}$ activation leads to $\mathrm{Ni}_{\mathrm{a}} \mathrm{-}$ in which nickel remains formally $\mathrm{Ni}(\mathrm{II})$, with a bridging hydride ligand and nearby proton. 
Oxidation to $\mathrm{Ni}(\mathrm{III})$, likely coupled to movement of a proton away from the active site, forms the $\mathrm{Ni}_{\mathrm{a}}-\mathrm{C}$ state. Whether completion of the catalytic cycle involves immediate proton and electron transfer to re-form $\mathrm{Ni}_{\mathrm{a}}-\mathrm{SI}$ directly from $\mathrm{Ni}_{\mathrm{a}}-\mathrm{C}$, or proceeds via the $\mathrm{Ni}(\mathrm{I})$ intermediate known as $\mathrm{Ni}_{\mathrm{a}}-\mathrm{L}$ in some or all hydrogenases remains uncertain. There is mounting evidence for $\mathrm{Ni}_{\mathrm{a}}-\mathrm{L}$ being an intermediate in catalysis for representative [NiFe] hydrogenases from different classes, and with a range of catalytic characteristics: the group $1 \mathrm{O}_{2}$-sensitive [NiFe] hydrogenase from Desulfovibrio vulgaris Miyazaki $\mathrm{F}^{23}$ and $\mathrm{O}_{2}$-tolerant $\mathrm{Hyd} 1$ from E. coli; ${ }^{21}$ and the group 3 soluble hydrogenase 1 from Pyrococcus furiosus. ${ }^{24,25}$

Key open questions relating to the [NiFe] hydrogenase catalytic cycle concern the mode of initial $\mathrm{H}_{2}$ interaction with $\mathrm{Ni}_{\mathrm{a}}$-SI, how $\mathrm{H}_{2}$ is heterolytically cleaved to leave a metal-bound hydride (and probably a nearby proton) in $\mathrm{Ni}_{\mathrm{a}}-\mathrm{R}$, as well as questions concerning how intimately proton and electron transfers are coupled through the remainder of the catalytic cycle. It has become increasingly apparent that outer sphere effects in the protein are important, and the best hydrogenase-inspired molecular catalysts incorporate proton transfer pathways. ${ }^{26-28}$ Understanding of residues involved in proton transfer in $[\mathrm{NiFe}]$ hydrogenase catalysis is still fairly rudimentary, however. ${ }^{29-32}$ A number of residues in the vicinity of the active site have been identified by site-selective mutagenesis as being critical to catalysis, with specific mutations greatly impairing, or completely suppressing, catalytic activity. ${ }^{29,33-36}$ More properly, the functional active site unit is better represented as a composite of the $[\mathrm{NiFe}]$ cluster, key amino acids, and the nearest ('proximal') iron sulfur electron relay cluster (Figure 2); these features of the protein 'gate' proton and electron transfer during catalysis. 


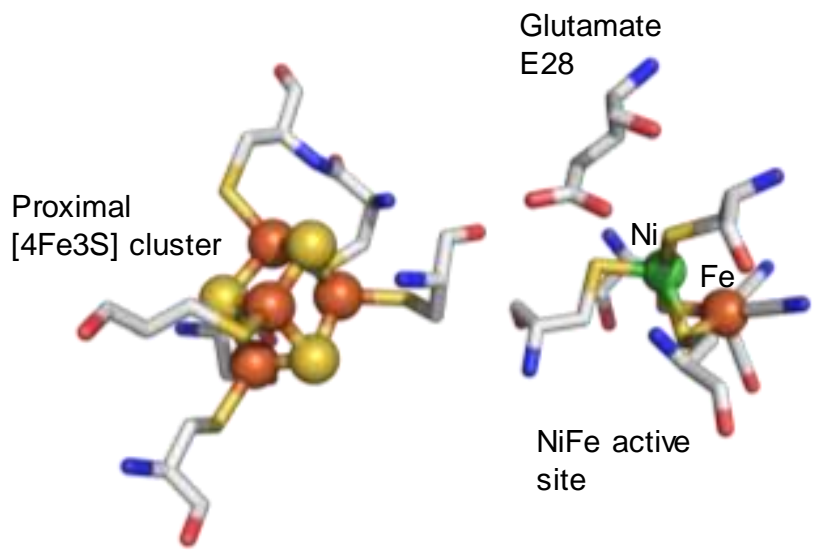

Figure 2. View of the [NiFe] hydrogenase active site and proximal cluster showing the position of the E28 residue, known to be important in proton transfer.

The data we present here are recorded on E. coli $\mathrm{Hyd} 1$, an $\mathrm{O}_{2}$-tolerant membrane-associated $[\mathrm{NiFe}]$ hydrogenase which natively exchanges electrons with the quinone pool via a membrane anchor cytochrome. ${ }^{37}$ Electron-relay chains, a common feature of many redox metalloenzymes, make hydrogenases well-equipped to exchange electrons with an electrode; the technique of protein film electrochemistry (PFE), ${ }^{3,4,38}$ in which the protein is adsorbed onto a carbon electrode and probed under direct electronic control has been applied extensively to Hydl and its variants. $^{34-36,39,11}$ Hyd1 also crystallizes readily; high resolution structures are available for the native enzyme and several variants. ${ }^{34-37}$ Therefore Hyd1 is an ideal model system to demonstrate how activity-based, spectroscopic and structural approaches can be combined to build a more comprehensive picture of enzyme function.

\section{Linking PFE and IR Spectroscopy: Protein Film IR Electrochemistry}

We have developed a method called protein film IR electrochemistry (PFIRE) that combines direct electrochemical control at a carbon electrode with simultaneous in situ IR spectroscopy. ${ }^{21,40}$ Enzyme is adsorbed onto high surface area $\left(>1000 \mathrm{~m}^{2} \mathrm{~g}^{-1}\right)^{41}$ carbon black particles, and the enzyme-modified particles are deposited as a macroscopic working electrode 
within a (spectro)electrochemical cell (Figure 3A). The high electrode surface area is necessary to provide sufficient material in the IR sampling area for spectroscopic detection; for some hydrogenase variants, covalent coupling to the surface has proved beneficial in increasing coverage and therefore IR signal. ${ }^{35}$ Rapid solution flow sustains fast electrocatalysis through supply of fresh substrate, and cyclic voltammograms analogous to those recorded using PFE are obtained in the presence of $\mathrm{H}_{2}$-saturated buffer (Figure 3B and C). (All potentials in this manuscript are quoted vs the standard hydrogen electrode, SHE.) We can also obtain information under non-turnover conditions equilibrated with Ar; Figure 3D shows an IR spectrum of Hyd1, recorded at $+356 \mathrm{mV}$, showing the $v_{\mathrm{CO}}$ and $v_{\mathrm{CN}}$ bands of the active site in the 'pure' oxidized, inactive Ni-B state.
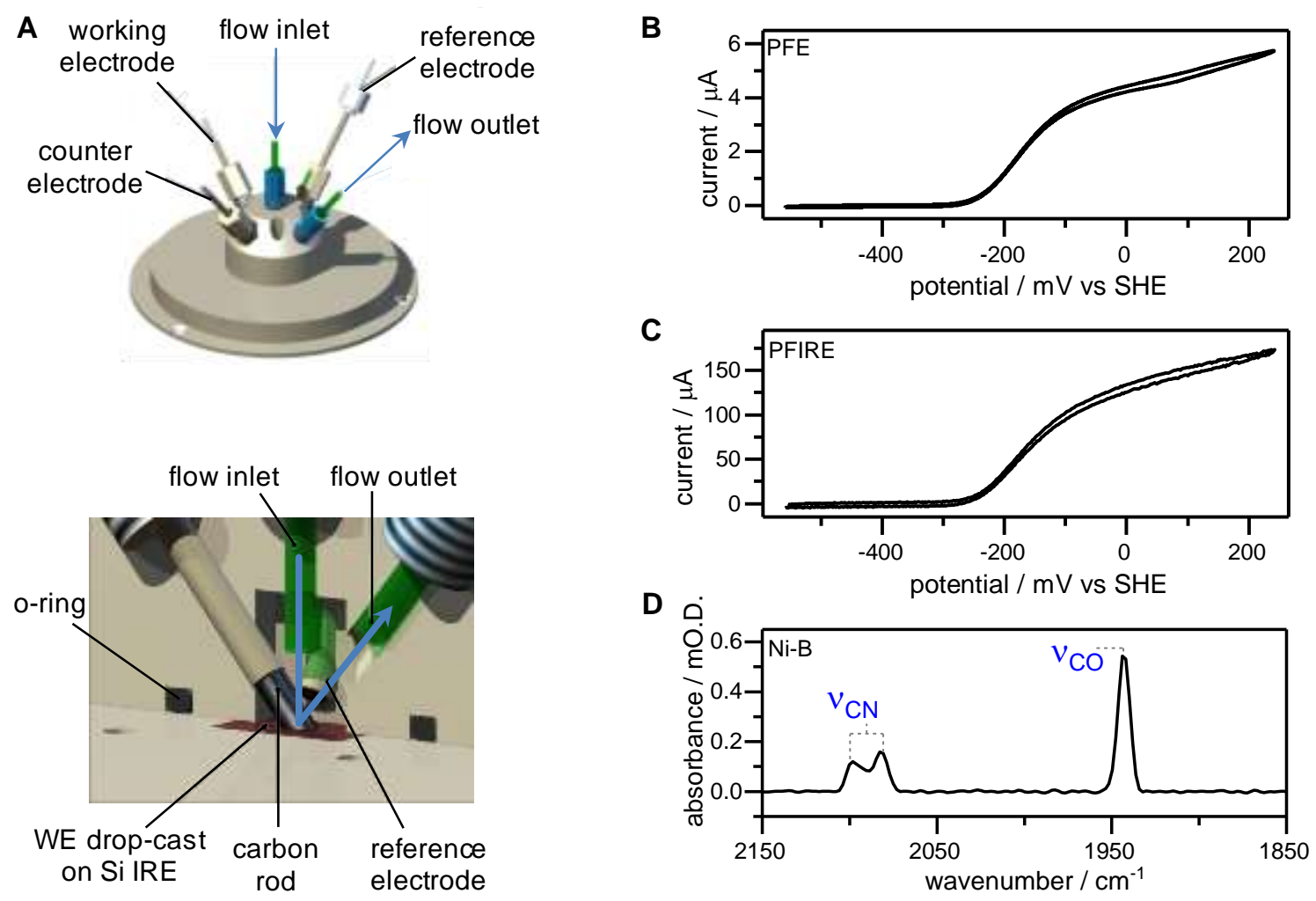

Figure 3. Protein film infrared electrochemistry combines protein film electrochemistry with in situ IR spectroscopy. (A) Spectroscopic-electrochemical flow cell used for PFIRE studies; (B) 
cyclic voltammogram of $E$. coli $\mathrm{Hyd} 1$ recorded under a $\mathrm{H}_{2}$ atmosphere at a rotating disc electrode using PFE; (C) cyclic voltammogram of E. coli Hyd1 recorded under a $\mathrm{H}_{2}$ atmosphere in the PFIRE spectroelectrochemical cell; (D) IR spectrum recorded at $+356 \mathrm{mV}$ showing active site $v_{\mathrm{CO}}$ and $v_{\mathrm{CN}}$ bands of the electrochemically-generated Ni-B redox state. Other conditions: $\mathrm{pH}$ 6.0 buffered electrolyte.

\section{Non-turnover studies}

Although no significant Faradaic current is observed for a Hyd1-modified electrode under an Ar atmosphere (Figure 4A), a redox titration of electrode-immobilized Hyd1 under these nonturnover conditions reveals the equilibrium ('static') behavior of the [NiFe] active site as the enzyme responds to electrode potential (Figure 4B). At pH 6.0 Hyd1 is strongly biased towards $\mathrm{H}_{2}$ oxidation and is very poor at proton reduction. ${ }^{42}$ Nevertheless, the fact that we are unable to obtain pure $\mathrm{Ni}_{\mathrm{a}} \mathrm{-}$. states even at very negative potentials is indicative of slow catalytic proton reduction under these conditions. Transformations between all redox states are fully reversible, ${ }^{21,40}$ allowing assignment of the various states of $\mathrm{Hyd} 1$ on the basis of their potential dependence, and not only by comparison to the substantial literature on [NiFe] hydrogenase redox chemistry in solution. ${ }^{19,22,43,44}$ The proportion of different states at each potential can be estimated from the $v_{\mathrm{CO}}$ intensities, and Figure $4 \mathrm{C}$ shows a graphic representation of a 'slice' of the redox titration at $-199 \mathrm{mV}$, where each bar represents the population of each redox state. 

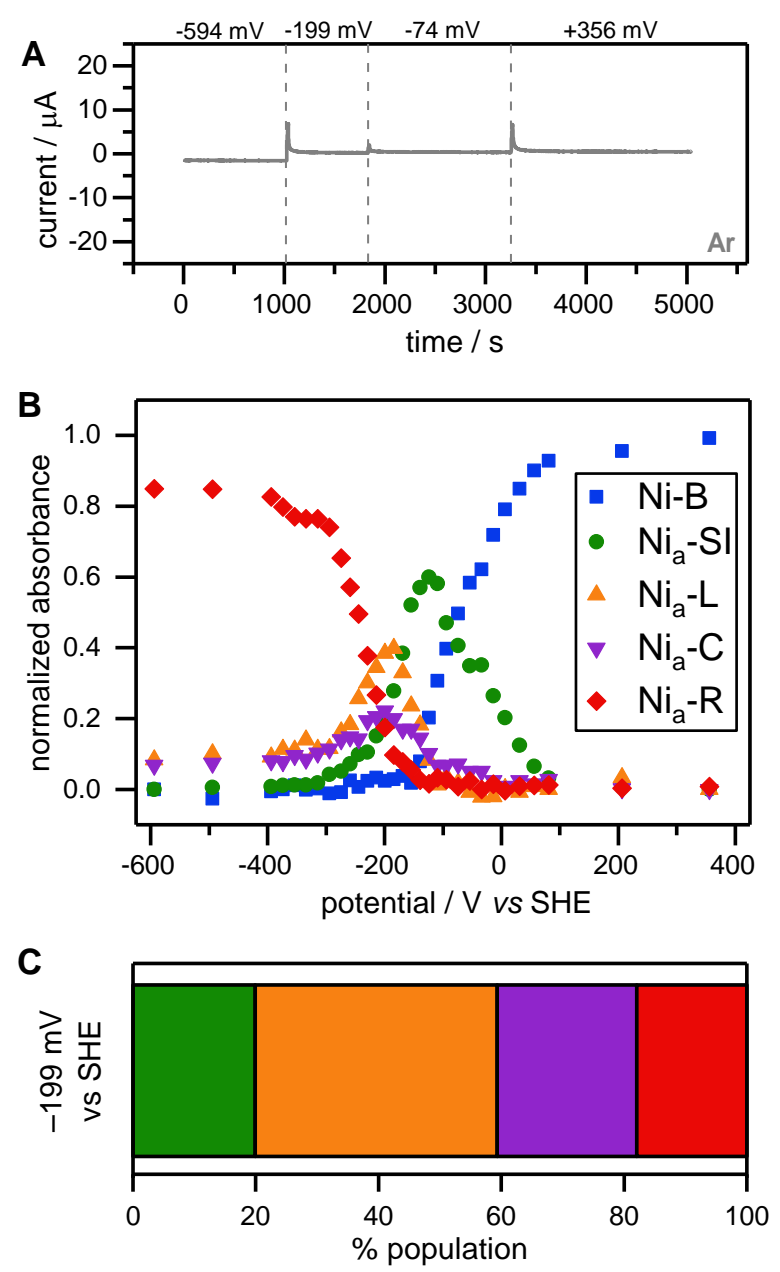

Figure 4. Direct electrochemical control coupled with infrared spectroscopy under non-turnover conditions (equilibrated with an argon atmosphere, $\mathrm{pH} 6.0$ buffer) for E. coli Hyd1 adsorbed on a carbon black electrode. (A) Electrochemical response at 4 different potentials; (B) redox titration showing how the population of different active site states changes with potential (recorded during a sequence of potential steps in the oxidative direction); (C) alternative representation of the population of active site states of Hydl at $-199 \mathrm{mV}$ as a column chart, color-coded according to the legend in panel $\mathrm{B}$ : $\mathrm{Ni}-\mathrm{B}$ (blue), $\mathrm{Ni}_{\mathrm{a}}-\mathrm{SI}$ (green), $\mathrm{Ni}_{\mathrm{a}}-\mathrm{L}$ (orange), $\mathrm{Ni}_{\mathrm{a}}-\mathrm{C}$ (purple), $\mathrm{Ni}_{\mathrm{a}}-\mathrm{R}$ (red). 


\section{Turnover}

The real value in coupling PFE with IR spectroscopy becomes apparent in studies of Hyd1 carried out under catalytic turnover in the presence of $\mathrm{H}_{2}$ where the rapid flow of electrons to the electrode at potentials above the proton/hydrogen couple $\left(E\left(\mathrm{H}^{+} / \mathrm{H}_{2}\right)=-354 \mathrm{mV}\right.$ at $\mathrm{pH} 6.0$ and 1 bar $\mathrm{H}_{2}$ ) and flow of $\mathrm{H}_{2}$-saturated solution sustain steady-state turnover during spectroscopic measurements (Figure 3A). ${ }^{21,40}$ A positive catalytic current is now observed at the electrode at $-74 \mathrm{mV}$ and $+356 \mathrm{mV}$ (Figure $5 \mathrm{~A}$ ), as enzymatic $\mathrm{H}_{2}$ oxidation channels electrons to the electrode. The current is very stable over the measurement time at $-74 \mathrm{mV}$, but decays slowly at $+356 \mathrm{mV}$ due to well-established oxidative inactivation. ${ }^{11,19,45}$ IR spectra recorded at these potentials are shown in Figure 5B: in contrast to the $+356 \mathrm{mV}$ spectrum under argon which shows only the inactive state, Ni-B (Figure 3D), the corresponding spectrum under $\mathrm{H}_{2}$ shows a distribution of states which reflect steady-state catalysis. Importantly, $\mathrm{Ni}_{\mathrm{a}}-\mathrm{L}$ states are populated suggesting that restoration of $\mathrm{Ni}_{\mathrm{a}}-\mathrm{SI}$ from $\mathrm{Ni}_{\mathrm{a}}-\mathrm{C}$ does go via a detectable $\mathrm{Ni}(\mathrm{I})$ intermediate. Together with evidence from time-resolved photolysis and light-induced potential jump experiments, this strongly implies involvement of the Ni(I) states in catalysis. ${ }^{15,23-25,46,47}$ The $v_{\mathrm{CO}}$ bands of $\mathrm{Ni}_{\mathrm{a}}-\mathrm{L}$ are very low in wavenumber for a terminal $\mathrm{CO}$ ligand, consistent with the presence of a metal-metal bond and extensive delocalization of electron density onto Fe. ${ }^{48}$ Two different forms of $\mathrm{Ni}_{\mathrm{a}}-\mathrm{L}$ and of $\mathrm{Ni}_{\mathrm{a}}-\mathrm{R}$ are observed in Hyd1 spectra, and these have been assigned to differentially protonated states. ${ }^{15,19,22,46}$ Spectroscopic data are also presented in Figure 5C as turnover minus non-turnover difference spectra to reflect changes in speciation in response to catalysis. Species that are populated in response to turnover (as opposed to simply a response to electrode potential) give rise to positive peaks. The speciation is highlighted graphically in Figure 5D, where the area of each bar represents the population of that state during 
steady-state turnover. At $+356 \mathrm{mV}$, some $\mathrm{Ni}-\mathrm{B}$ is present even during turnover under $\mathrm{H}_{2}$, consistent with the high potential inactivation evidenced by decay in catalytic current (Figure $5 \mathrm{~A})$. Inactivation is fully reversible when the potential is stepped to less positive values. ${ }^{21,40}$
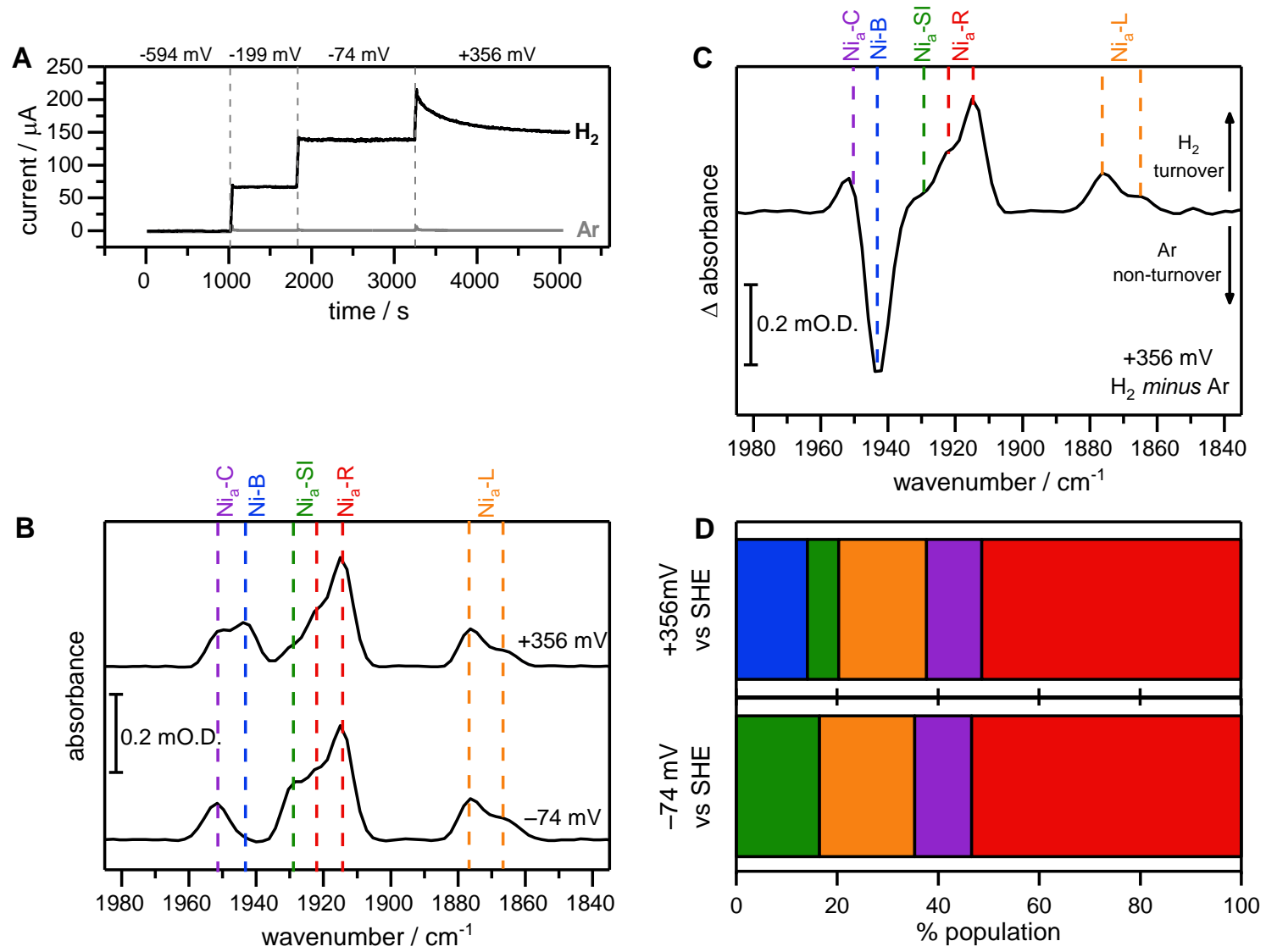

Figure 5. Protein film IR electrochemistry of E. coli Hydl under turnover conditions $\left(1 \mathrm{bar} \mathrm{H}_{2}\right)$.

(A) Electrocatalytic current response, compared to the corresponding current in the absence of turnover; (B) IR spectra recorded at $-74 \mathrm{mV}$ and $+356 \mathrm{mV}$ during steady-state $\mathrm{H}_{2}$ oxidation; (C) $\mathrm{H}_{2}$ turnover minus Ar non-turnover difference spectrum at $+356 \mathrm{mV}$; (D) column charts showing the steady-state distribution of active site states at $-74 \mathrm{mV}$ and $+356 \mathrm{mV}$ during $\mathrm{H}_{2}$ oxidation.

\section{The effect of $\mathrm{pH}$}

A major advantage of PFE is that measurements can be made on the same enzyme sample whilst perturbing solution conditions, such as substrate and inhibitor concentration, or $\mathrm{pH} .^{2-4,11,39}$ 
These advantages are retained by PFIRE, with the additional benefit of observing, spectroscopically, chemical changes brought about by the perturbation. Solution $\mathrm{pH}$ has a significant effect on [NiFe] hydrogenase catalysis: E. coli $\mathrm{Hyd} 1$ becomes good at $\mathrm{H}_{2}$ production at low $\mathrm{pH}^{42}$ By varying solution $\mathrm{pH}$ we found clear evidence for an acid-base equilibrium between the $\mathrm{Ni}_{\mathrm{a}}-\mathrm{C}$ and $\mathrm{Ni}_{\mathrm{a}}-\mathrm{L}$ states of Hyd $1{ }^{49}$ The two $\mathrm{Ni}_{\mathrm{a}}-\mathrm{L}$ states observed for Hyd 1 do not share the same $\mathrm{pH}$ dependence (Figure 6), strongly implying the existence of distinct proton acceptor sites. ${ }^{22}$ Similar $\mathrm{pH}$ dependence of $\mathrm{Ni}_{\mathrm{a}}-\mathrm{L}$ states has been reported for the [NiFe] hydrogenase from $D$. vulgaris $\mathrm{MF}$, where an additional $\mathrm{Ni}_{\mathrm{a}}-\mathrm{L}$ state was formed at high $\mathrm{pH}{ }^{46}$ Taken together with transient absorption spectra following a laser-induced potential jump ${ }^{15,24}$ these data imply multiple $\mathrm{Ni}_{\mathrm{a}}-\mathrm{L}$ states can be involved in catalysis sequentially.

It has been suggested that concerted proton and electron transfer takes place during the $\mathrm{Ni}_{\mathrm{a}}-\mathrm{L} \rightarrow \mathrm{Ni}_{\mathrm{a}}-\mathrm{SI}$ transition. ${ }^{24}$ It is also known that the proximal iron-sulfur cluster (Figure 2) must be in an oxidized state in order to accept an electron from the [NiFe] active site; $\mathrm{Ni}_{\mathrm{a}}-\mathrm{SI}$ formation following photolysis of $\mathrm{Ni}_{\mathrm{a}}-\mathrm{C}$ only occurs when the proximal cluster is oxidized. ${ }^{23,24}$ Therefore, the $\mathrm{Ni}_{\mathrm{a}}-\mathrm{C} \rightarrow \mathrm{Ni}_{\mathrm{a}}-\mathrm{L} \rightarrow \mathrm{Ni}_{\mathrm{a}}-\mathrm{SI}$ steps during the catalytic cycle are 'gated' by both the proximal cluster and the proton acceptor site(s). Unlike the highly-conserved nature of amino acid residues surrounding the $[\mathrm{NiFe}]$ active site, distinct proximal cluster structures have been identified in hydrogenases with different catalytic characteristics. ${ }^{19,44,50-53}$ Simplistically, the defining proximal cluster features are: (a) the ability to transfer either only one, or two electrons; and (b) the cluster redox potential relative to $E\left(\mathrm{H}^{+} / \mathrm{H}_{2}\right)$. In $\mathrm{O}_{2}$-sensitive group 1 hydrogenases, such as $D$. vulgaris $\mathrm{MF}$, the redox potential of the [4Fe-4S] proximal cluster is in the region of $E\left(\mathrm{H}^{+} / \mathrm{H}_{2}\right)$, whilst $\mathrm{O}_{2}$-tolerant hydrogenases such as $E$. coli $\mathrm{Hyd} 1$ have an unusual high-potential [4Fe-3S] proximal cluster. The probability that the proximal cluster is oxidized, and thus can accept the 
electron needed to complete the catalytic cycle, is greater for $\mathrm{O}_{2}$-sensitive relative to $\mathrm{O}_{2}$-tolerant [NiFe] hydrogenases. It is possible that electron transfer is more limiting for $\mathrm{O}_{2}$-tolerant hydrogenases, allowing more time for acid-base chemistry around the active site, and making a wider range of $\mathrm{Ni}_{\mathrm{a}}-\mathrm{L}$ states accessible during turnover: the proton released from $\mathrm{Ni}_{\mathrm{a}}-\mathrm{C}$ can travel further before an electron transfers to the proximal cluster. This provides a tentative mechanistic rationale for the $\mathrm{Ni}_{\mathrm{a}}-\mathrm{L}$ states observed in $\mathrm{O}_{2}$-tolerant hydrogenases, which tend to have very low $v_{\mathrm{CO}}$. In these $\mathrm{Ni}_{\mathrm{a}} \mathrm{L}$ states the proton is likely to be further removed from the primary coordination sphere of the $[\mathrm{NiFe}]$ active site. ${ }^{22}$

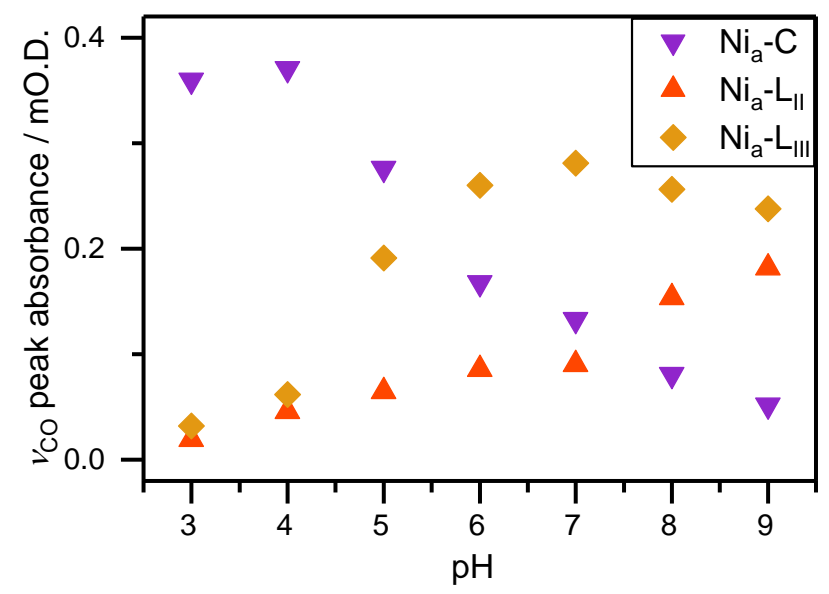

Figure 6. The relative populations of $\mathrm{Ni}_{\mathrm{a}}-\mathrm{C}$ and $\mathrm{Ni}_{\mathrm{a}}-\mathrm{L}$ are $\mathrm{pH}$ dependent. Additionally, the $\mathrm{Ni}_{\mathrm{a}}-\mathrm{L}$ states observed in $E$ coli Hyd1 do not share the same $\mathrm{pH}$ dependence, implying multiple proton acceptor sites.

\section{PFIRE applied to a variant of Hyd1 with impaired proton transfer: E28Q}

Site-directed mutagenesis is widely used by molecular biologists to probe the importance and role of specific amino acids on enzyme activity in order to gain mechanistic insight into the native enzymes. Assumptions are often made that mutations only have a single well-defined effect on catalysis, commonly on the basis that active sites 'look' the same as judged from 
structural data on 'as-isolated' or inactive states (or on a limited subset of easily-accessible active states), or from single spectroscopic measurements under non-turnover conditions. However a mutation near the active site may have additional unintended effects on electronic structure, dynamics, and protonation. The power of combining activity-based measurements on sitedirected variants with in situ spectroscopic methods remains under-utilized for detailed mechanistic studies.

As a case study, we consider a highly-conserved glutamate (residue E28 in E. coli Hyd1 numbering), located within $4 \AA$ of the terminal cysteine residues of the $[\mathrm{NiFe}]$ active site (Figure 2) and widely reported to be critical for catalytic proton transfer during the catalytic cycle. ${ }^{29,31,33,35,54,55}$ Mutation of glutamate 28 to glutamine (Q, to form the E28Q variant in Hyd1), greatly suppressing the proton-transfer ability of the site by raising the $\mathrm{pK}_{\mathrm{a}}$, has been shown to attenuate substantially the activity of $\mathrm{E} \rightarrow \mathrm{Q}$ variants in a range of hydrogenases. These observations, coupled with apparently unaltered active site redox chemistry or structure, have led to consideration of glutamate E28 as the essential 'gating' residue for proton transfer during catalysis. $^{29}$ This interpretation may be over-simplistic, however, and belies the fact that: (a) [NiFe] hydrogenase active site 'cavities' contain not only highly conserved amino acid residues but also highly conserved, crystallographically ordered water molecules that can also act as $\mathrm{H}^{+}$ transfer sites (at least within the active site cavity); ${ }^{34}$ and (b) $\mathrm{E} \rightarrow \mathrm{Q}$ variants do in general retain non-negligible residual activities of up to $50 \%{ }^{31}$ It is possible that there could be sufficient adaptability in the vicinity of the $[\mathrm{NiFe}]$ active site to allow for proton exit via multiple initial donor sites and indeed several proton transfer pathways have been postulated, not all explicitly involving glutamate E28. ${ }^{29-32}$ 
Using a combination of non-turnover and steady-state turnover PFIRE measurements, we can compare active site chemistry of E28Q Hyd1 with the native enzyme. ${ }^{35}$ Figure 7A shows a difference spectrum (steady-state $\mathrm{H}_{2}$ oxidation minus non-turnover under Ar) of E28Q Hyd1 at $-100 \mathrm{mV}$. In line with previous reports we find that the non-turnover redox behavior of the [NiFe] active site remains largely unaltered (negative bands, Figure 7A), and further that the $v_{\mathrm{CO}}$ and $v_{\mathrm{CN}}$ peak positions of all redox states remains unchanged, although in contrast to native Hyd1 we see no conclusive evidence for $\mathrm{Ni}_{\mathrm{a}}-\mathrm{L}$ formation under any conditions in E28Q Hyd1.

Figure 7B shows a reinterpretation of PFIRE spectra during steady-state $\mathrm{H}_{2}$ oxidation, to show the distribution of catalytic states observed during turnover. States of the [NiFe] active site observed during steady-state catalysis are indicative of 'bottlenecks', or limiting steps within the catalytic cycle. In a cyclic reaction, if a particular step $X \rightarrow Y$ is rate limiting we expect to observe a large proportion of ' $\mathrm{X}$ ' during steady-state catalysis as its formation is fast relative to onward reaction to form ' $\mathrm{Y}$ '. The fact that we observe only $\mathrm{Ni}_{\mathrm{a}}-\mathrm{R}$ and $\mathrm{Ni}_{\mathrm{a}}-\mathrm{C}$ during steady-state $\mathrm{H}_{2}$ oxidation by E28Q Hyd 1 implies that the initial activation of $\mathrm{H}_{2}\left(\mathrm{Ni}_{\mathrm{a}}-\mathrm{SI} \rightarrow \mathrm{Ni}_{\mathrm{a}}-\mathrm{R}\right)$ is still fast, and that the catalytic 'bottleneck' lies during the conversion of $\mathrm{Ni}_{\mathrm{a}}-\mathrm{C}$ to $\mathrm{Ni}_{\mathrm{a}}-\mathrm{SI}$ (Figure 1). Since E28Q Hyd1 achieves a significant concentration of $\mathrm{Ni}_{\mathrm{a}} \mathrm{C}$ during steady-state turnover we can conclude the transitions $\mathrm{Ni}_{\mathrm{a}}-\mathrm{SI} \rightarrow \mathrm{Ni}_{\mathrm{a}}-\mathrm{R} \rightarrow \mathrm{Ni}_{\mathrm{a}}-\mathrm{C}$ are not reliant on glutamate $\mathrm{E} 28$, and that the first proton transfer step during $\mathrm{H}_{2}$ oxidation is unaffected by the $\mathrm{E} \rightarrow \mathrm{Q}$ mutation. These observations imply that the immediate proton transfer donor is probably different during both the $\mathrm{Ni}_{\mathrm{a}}-\mathrm{C} \rightarrow \mathrm{Ni}_{\mathrm{a}}-\mathrm{SI}$ and $\mathrm{Ni}_{\mathrm{a}}-\mathrm{R} \rightarrow \mathrm{Ni}_{\mathrm{a}}-\mathrm{C}$ transitions.

Despite almost complete loss of catalytic and $\mathrm{D}^{+} / \mathrm{H}^{+}$exchange activity, the $\mathrm{H}_{2}$ cleavage ability of the equivalent $\mathrm{E} \rightarrow \mathrm{Q}$ variant of the [NiFe]-hydrogenase from Desulfovibrio fructosovorans remained unchanged based on para $-\mathrm{H}_{2} /$ ortho- $\mathrm{H}_{2}$ exchange. ${ }^{29}$ Reductive activation of this variant 
led to formation of $\mathrm{Ni}_{\mathrm{a}}-\mathrm{C}$ and $\mathrm{Ni}_{\mathrm{a}}-\mathrm{R},{ }^{29}$ a further example whereby the $\mathrm{Ni}_{\mathrm{a}}-\mathrm{C}$ state is an easily accessible catalytic 'bottleneck'. Proton and/or electron transfer during the $\mathrm{Ni}_{\mathrm{a}}-\mathrm{C} \rightarrow \mathrm{Ni}_{\mathrm{a}}-\mathrm{SI}$ transition must therefore be limiting in the $\mathrm{E} \rightarrow \mathrm{Q}$ variants. Conversely, our hypothesis that glutamate $\mathrm{E} 28$ is not critical to the $\mathrm{Ni}_{\mathrm{a}}-\mathrm{R} \rightarrow \mathrm{Ni}_{\mathrm{a}}-\mathrm{C}$ transition is in contrast to previous conclusions, based on slowed proton transfer during this step at $\mathrm{pH}$ values above the likely $\mathrm{pK}_{\mathrm{a}}$ of glutamate in the equivalent $\mathrm{E} \rightarrow \mathrm{Q}$ variant of the soluble hydrogenase 1 from P. furiosus. ${ }^{15,24}$ The relatively high residual activity of several $\mathrm{E} \rightarrow \mathrm{Q}$ variants implies the $[\mathrm{NiFe}]$ active site has proton-transfer flexibility; if proton transfer were completely blocked catalysis would 'turn off'. The identity (or identities) of the primary proton acceptor following $\mathrm{H}_{2}$ activation, and the immediate proton transfer site during the $\mathrm{Ni}_{\mathrm{a}}-\mathrm{R} \rightarrow \mathrm{Ni}_{\mathrm{a}}-\mathrm{C}$ transition, are clear targets for future study. It will be interesting to see if an 'intermediate' proton transfer site emerges that satisfies both our observations and the apparent $\mathrm{pK}_{\mathrm{a}}$ requirements. 

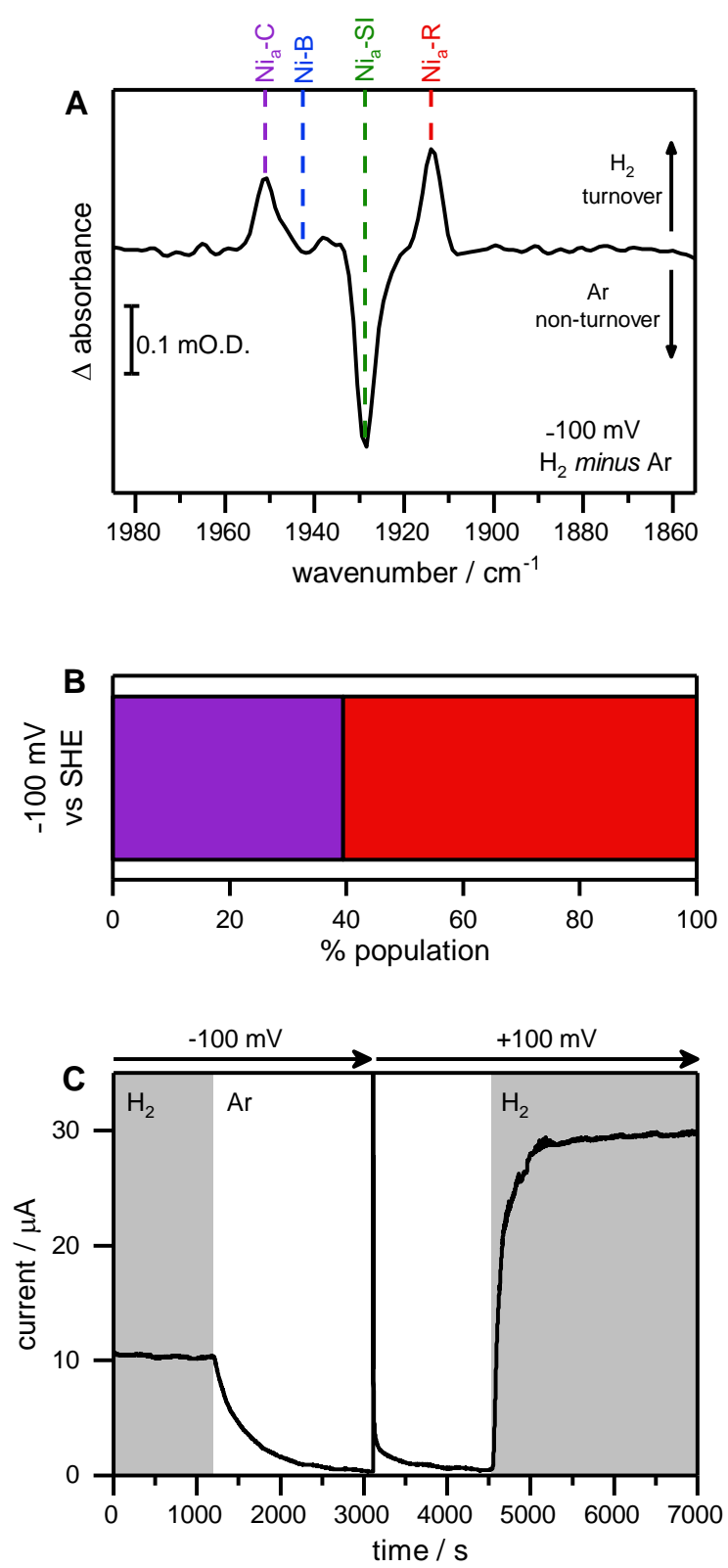

Figure 7. Steady-state PFIRE measurements during $\mathrm{H}_{2}$ oxidation by E28Q Hyd1 suggest that the $E \rightarrow Q$ mutation only blocks one of the two proton transfer steps during catalysis. (A) Steady-state $\mathrm{H}_{2}$ oxidation minus Ar non-turnover difference spectrum at $-100 \mathrm{mV}$ vs $\mathrm{SHE}, \mathrm{pH}$ 6.0. (B) Column chart showing the steady-state population of the E28Q active site during $\mathrm{H}_{2}$ oxidation. (C) Steady-state $\mathrm{H}_{2}$ oxidation current is maintained under a $\mathrm{H}_{2}$ atmosphere, confirming sustained turnover during these measurements. 

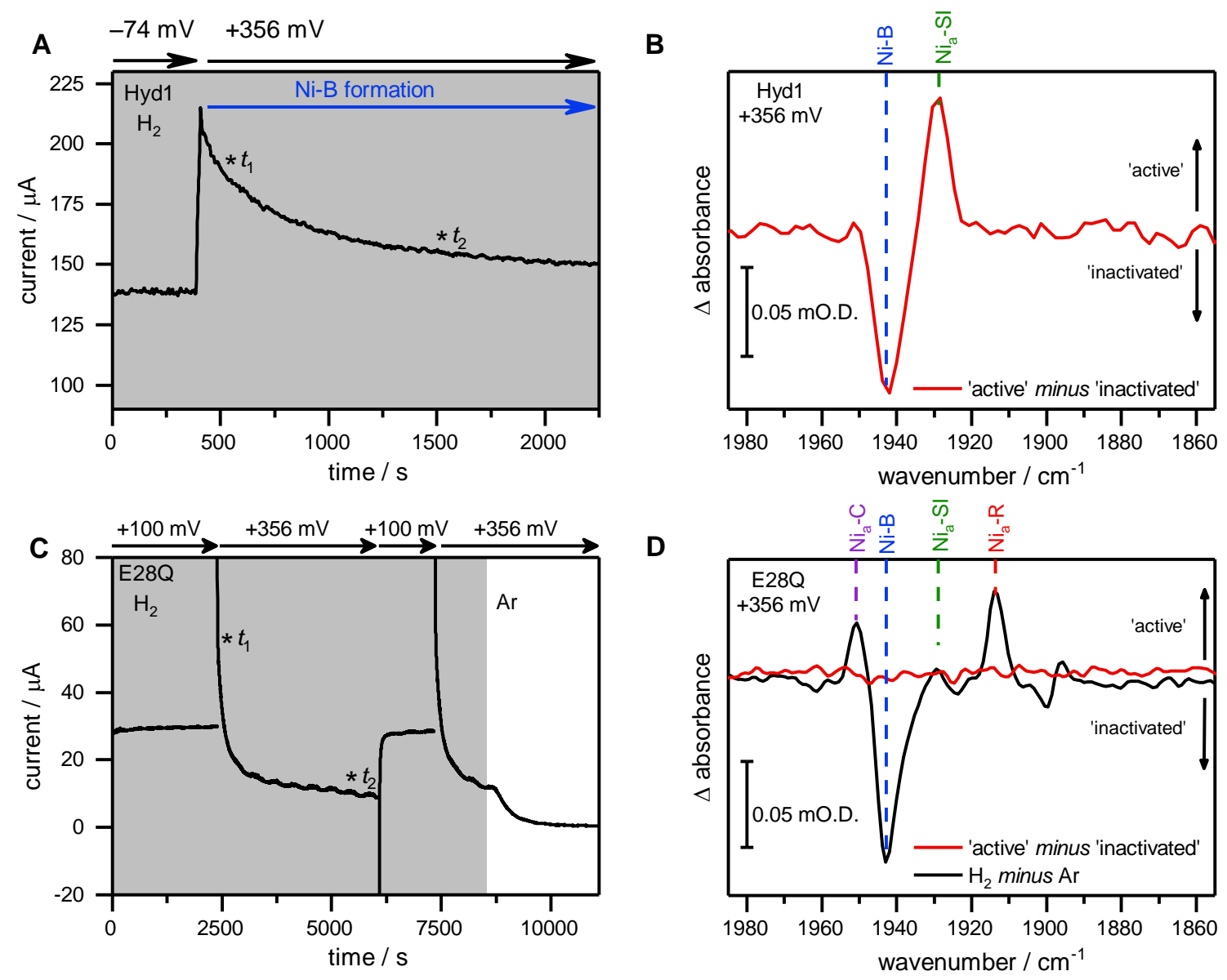

Figure 8. High potential inactivation of native and E28Q Hydl under a $\mathrm{H}_{2}$ atmosphere. Monotonic loss of current at $+356 \mathrm{mV}$ is observed for native Hyd1 (A), and oxidative inactivation results in conversion of a proportion of the active site to the inactive Ni-B redox state (B). Similar loss of current is observed with E28Q (C), but now high potential inactivation is not accompanied by $\mathrm{Ni}-\mathrm{B}$ formation ( $\mathrm{D}$, red), despite $\mathrm{Ni}-\mathrm{B}$ being a readily-accessible state under non-turnover conditions (black). 'Active' minus 'inactivated' difference spectra in (B) and (D) calculated as $t_{1}$ minus $t_{2}$ from spectra recorded as indicated in (A) and (C), adapted from data in reference 35 .

Native E. coli $\mathrm{Hyd} 1$ experiences inactivation at high potentials during $\mathrm{H}_{2}$ oxidation, shown by a monotonic decrease in catalytic current in Figure 8A. High potential inactivation of [NiFe] 
hydrogenases under anaerobic conditions is typically assumed to be 'oxidative' inactivation, resulting in formation of the oxidized, inactive Ni-B state of the active site. However there is little direct experimental evidence to correlate inactivation with Ni-B formation during catalytic turnover. In PFIRE studies on native Hydl we did observe in situ Ni-B formation at high potentials during $\mathrm{H}_{2}$ oxidation, providing experimental confirmation of the widely-accepted interpretation (Figure 8B). Similar high potential inactivation was observed with E28Q Hyd1 (Figure 8C), but in this instance PFIRE studies did not reveal Ni-B formation during high potential inactivation (Figure $8 \mathrm{D}$, red line): the fairly flat difference spectrum shows minimal effects at the active site accompanying the significant loss of catalytic current. In contrast, removal of $\mathrm{H}_{2}$ by flushing with $\mathrm{Ar}$ (difference spectrum in Figure 8D, black line) does result in rapid active site oxidation and Ni-B formation, proving that Ni-B is still an accessible state. This observation implies that there must be alternative high-potential inactivation processes that can take place during turnover (perhaps linked to super-oxidation of the proximal iron sulfur cluster), ${ }^{35}$ and reinforces the importance of in situ spectroscopic techniques such as PFIRE. The fact that no new active site states (i.e. no new $v_{\mathrm{CO}}$ bands) are observed during the inactivation process suggests that the inactivation involves another center in the protein. This could be explained by super-oxidation of the unusual proximal iron sulfur cluster of Hyd1 which is likely to be slow to re-reduce due to a significant structural change accompanying the superoxidized/oxidized redox couple. ${ }^{35,37,56}$ In situ spectroscopic data are lacking on other hydrogenases under turnover conditions, and so the generality of Ni-B formation during inactivation is largely unexplored. Electrochemistry alone can only identify relative activities or the existence of inactivation processes, but cannot definitively diagnose the underlying active site chemistry. 


\section{Single crystal microspectroscopy coupled to electrochemical control}

In the same way that in situ spectroscopy is increasingly important in mechanistic studies of redox enzymes, spectroscopic methods are required to complement structural studies of metalloproteins. ${ }^{57}$ Single crystal microspectroscopic methods to confirm the integrity, physiological relevance, and redox state of crystallized proteins, and to assess radiation damage are becoming more common. ${ }^{57-60}$ Such techniques have been applied to on- and off-line monitoring, but there is a need to develop methods which offer control over the oxidation state of crystallized proteins, or go beyond 'static' study of proteins in the crystalline state. For complex enzymes with multiple redox states, it can be difficult to structurally characterize all states due to challenges in crystal sample preparation. ${ }^{59}$ The state of crystallized proteins can be manipulated by soaking in reductants, oxidants, substrates or inhibitors, or the protein can be chemically treated prior to crystallization. We combined these ideas with electrochemical control over a pool of redox mediators spanning the potential range relevant to redox states of $[\mathrm{NiFe}]$ hydrogenases, using a custom-designed IR microspectroscopic-electrochemical cell (Figure 9). ${ }^{14}$ 

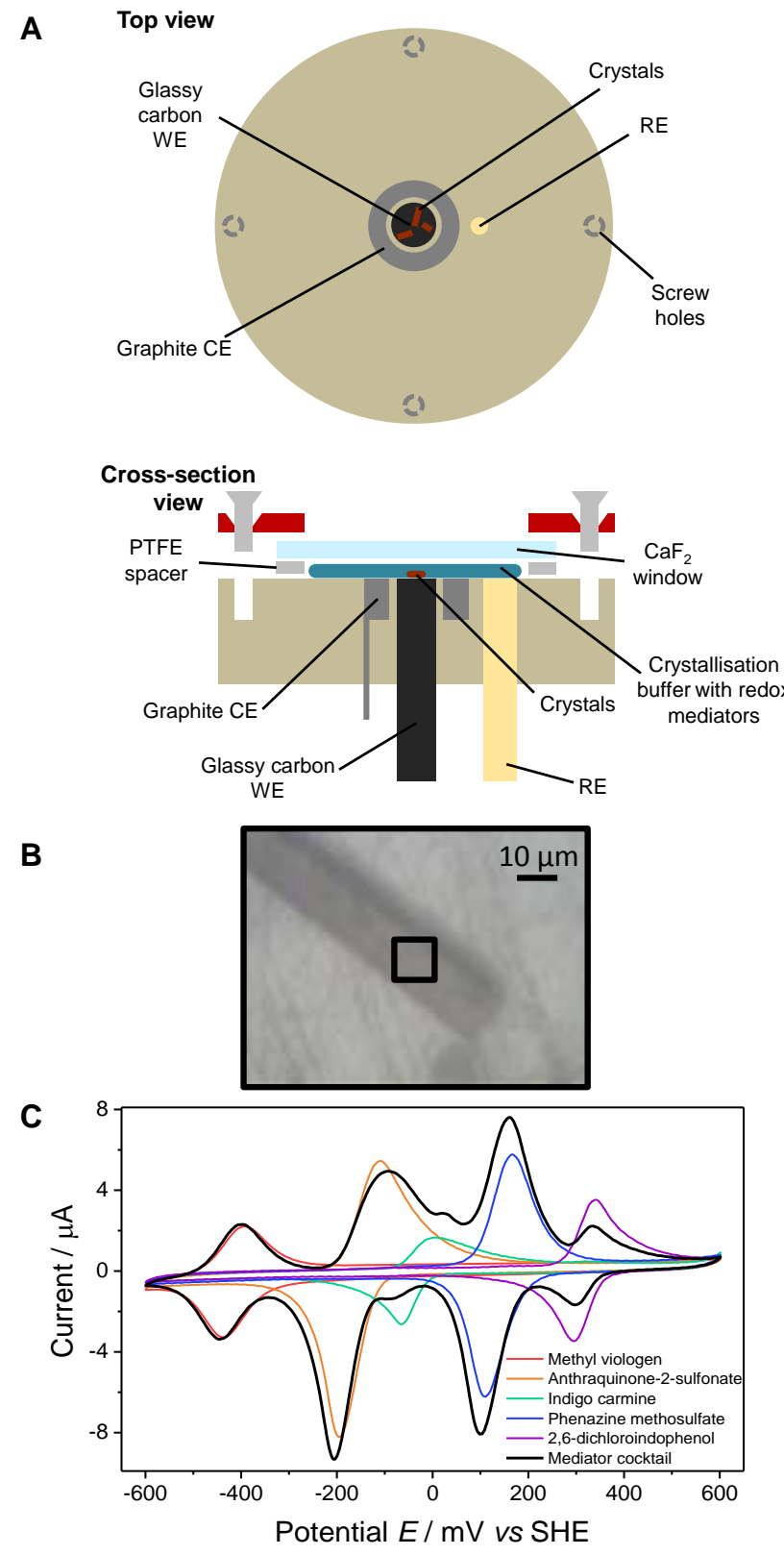

Figure 9. A microspectroscopic-electrochemical cell for single crystal spectroscopy. (A) Schematic diagram, showing arrangement of working, counter, and reference electrodes (WE, CE, RE), and crystal sample; (B) Visible image of a Hydl crystal on the working electrode, showing the area used to collect spectra; (C) Cyclic voltammograms of individual redox mediator solutions and the total mediator cocktail: $1 \mathrm{mM}$ each of methyl viologen, 
anthraquinone-2-sulfonate, indigo carmine, phenazine methosulfate, and 2,6-dichloroindophenol in crystallization buffer.

Whereas previous in crystallo spectroscopic studies have largely focused on inactive or inhibited states of redox enzymes ${ }^{61,62}$ we have shown that the crystalline state can be considered as a dynamic system, offering the possibility of unlocking insight into how complex enzymes function. Together with diffraction-limited synchrotron IR microspectroscopy, electrochemical control probes chemical transformations of the hydrogenase active site within single crystals during catalysis. ${ }^{14}$ Redox control over the whole crystallized sample appears to be uniform, and fine potential control allows accumulation of all long-lived redox states of the [NiFe] active site (Figure 10A). Importantly the peak positions and equilibrium potential dependencies of redox states observed in crystallo, in solution, and in PFIRE measurements are the same. Redox transitions involving chemical steps (for example proton transfer) appear to be retarded in the crystalline state. This is shown by the time-dependent formation of two $\mathrm{Ni}_{\mathrm{a}}-\mathrm{R}$ states in Hyd 1 crystals (Figure 10B), in contrast to the appearance of these states together under turnover in PFIRE measurements (see Figure 5B). The existence of multiple $\mathrm{Ni}_{\mathrm{a}}-\mathrm{R}$ states is well documented, and although the relative population of different $\mathrm{Ni}_{\mathrm{a}}-\mathrm{R}$ states is known to be $\mathrm{pH}$ dependent there is no general mechanistic rationalization of these observations. The $\mathrm{pH}$ dependence implies structural differences in protonation state, and the observation that two $\mathrm{Ni}_{\mathrm{a}}-\mathrm{R}$ substates form at different rates in crystalline Hydl suggests that individual $\mathrm{Ni}_{\mathrm{a}}-\mathrm{R}$ states may represent sequential proton transfer steps away from the [NiFe] active site following initial $\mathrm{H}_{2}$ activation. There is also the tantalizing prospect that one of the $\mathrm{Ni}_{\mathrm{a}}-\mathrm{R}$ states could be closely related to the Michaelis-Menten complex of $\mathrm{H}_{2}$ at the active site. 

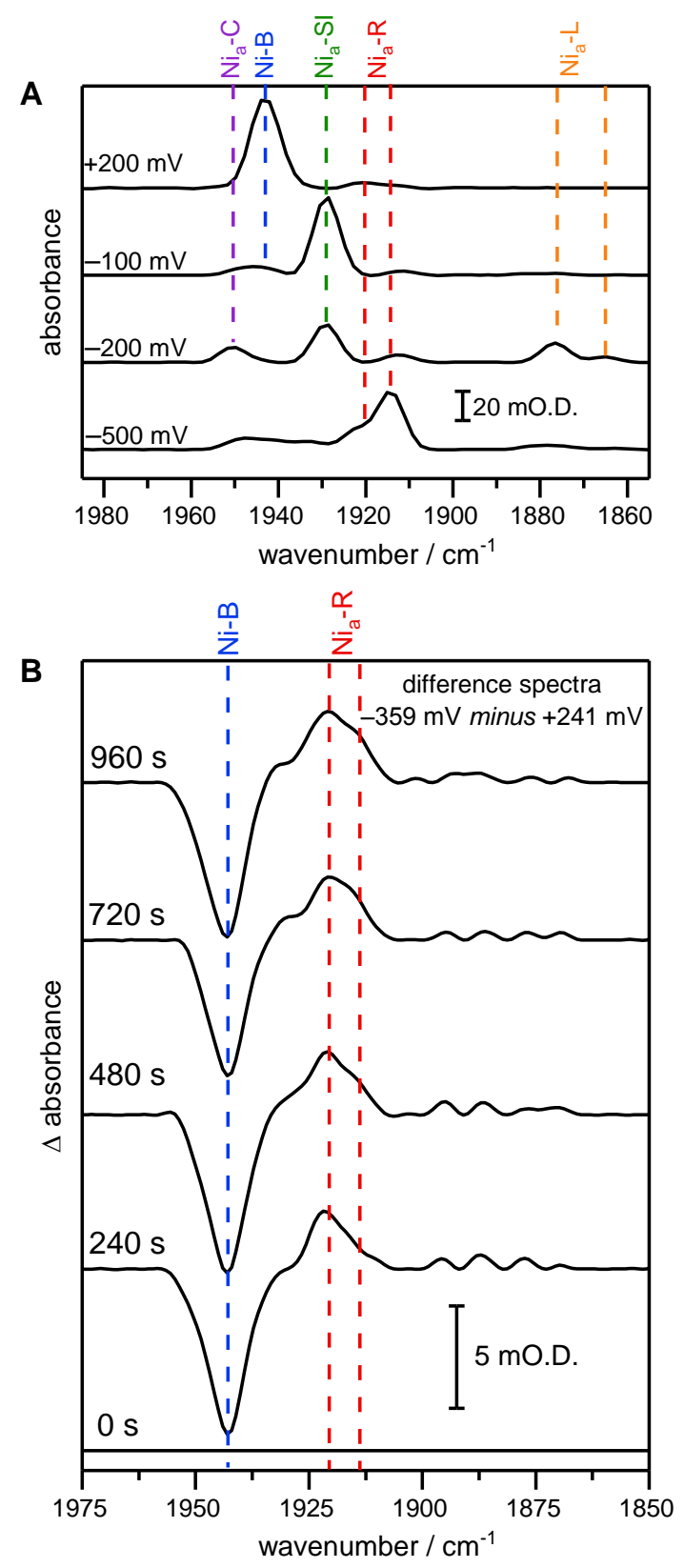

Figure 10. Single crystal IR spectroscopy of E. coli Hyd1 under $\mathrm{N}_{2}$. (A) Spectra recorded as a function of potential demonstrate accumulation of all active site states in crystallo. (B) Difference spectra recorded as a function of time after a reducing potential step resolve different time dependencies for formation of two $\mathrm{Ni}_{\mathrm{a}}-\mathrm{R}$ sub-states; reproduced with permission from Ash et al. ${ }^{14}$

\section{Discussion}


The examples we have presented here from studying E. coli Hyd1 using IR spectroscopy applied in different ways demonstrate the value of coupling activity-based measurements with spectroscopy. The observation that high potential inactivation of the E28Q variant of Hyd1 does not arise from formation of the well-known Ni-B state but seems to be associated with an oxidation of the proximal iron sulfur clusters challenges common assumptions about hydrogenase inactivation and highlights possible pitfalls in over-interpreting current-activity data from PFE alone. We also show the power in carrying out in situ spectroscopy during catalytic turnover to report on steady-state intermediates during catalysis. Using this approach, we have been able to strengthen the evidence for involvement of the $\mathrm{Ni}(\mathrm{I})$ intermediate $\mathrm{Ni}_{\mathrm{a}}-\mathrm{L}$ in the [NiFe] hydrogenase catalytic cycle, for example, and to diagnose catalytic 'bottlenecks' introduced by the targeted E28Q mutation in Hyd1, allowing us to propose a critical mechanistic role for $\mathrm{E} 28 \mathrm{Q}$ in the second proton transfer during $\mathrm{H}_{2}$ oxidation.

The PFIRE method is particularly valuable for studying hydrogenases, as intrinsic $\mathrm{CO}$ and $\mathrm{CN}^{-}$ ligands are strong IR absorbers and report directly on changes in redox state. Since the protein is immobilized on the electrode, variable temperatures or $\mathrm{pH}$ conditions can readily be applied in PFIRE measurements by controlling the temperature or $\mathrm{pH}$ of the buffered electrolyte.

We further show that IR spectroscopy combined with electrochemical control can be extended to the crystalline state, where the enzyme can still be regarded as a dynamic system able to cycle through redox states relevant to catalysis. This is a valuable tool for mechanistic studies, as chemical steps seem to be slowed in crystallo, so that, for example, formation of different $\mathrm{Ni}_{\mathrm{a}}-\mathrm{R}$ states could be kinetically resolved. It will also be extremely useful to link this control to structure determination. It is possible to generate several redox states of Hyd 1 in almost pure form at specific potentials (see Figure 4B), which could enable structural study of states that 
have thus far been inaccessible for X-ray diffraction. Preliminary results (unpublished) show no noticeable drop in X-ray diffraction quality for crystals of Hyd1 after electrochemical manipulation. It will also be important to use spectroscopic methods to characterize crystals that have been generated for structural study in order to correlate known catalytic and solution behavior of redox states to atomic resolution structures. We therefore see possibilities for a unified approach to bioinorganic chemistry, with coherent crossover of methods from solution, electrochemical, and solid state studies helping to bridge gaps in mechanistic understanding and reconcile confusion between different types of data set.

Where else will this be useful? There have been several recent fascinating X-ray crystallographic studies of metalloproteins that are yet to be reconciled with solution behavior of these enzymes. Rees and coworkers reported a CO bound structure of molybdenum nitrogenase where the molybdenum iron catalytic cluster has opened up with loss of sulfide to coordinate the inhibitor. ${ }^{63}$ IR spectroscopy on crystals of the CO-inhibited nitrogenase would be valuable in relating this structure to the wealth of CO-inhibited states observed spectroscopically during stopped-flow studies of $\mathrm{CO}$ inhibition during turnover. ${ }^{64}$ Other valuable systems to target with a suite of turnover spectroelectrochemical studies and in crystallo spectroscopic studies will be the molybdopterin enzymes nitrate reductase and formate dehydrogenase where disparate mechanisms have been suggested for similar enzyme active sites. ${ }^{65}$ Carbon monoxide dehydrogenase is another fast turnover enzyme for which it is difficult to prepare samples for spectroscopy in catalytically relevant states, and the in situ and in crystallo substrate-turnover methods may provide new mechanistic understanding.

In conclusion, we hope that solution, electrode and crystal methods will be utilized in a much more unified way in future studies in bio-inorganic chemistry so that information can be 
reconciled more readily across different sample types. It will also be important to apply the same range of spectroscopic and activity-based methods to enzymes from different organisms in order to understand how general some of these mechanistic steps are to metalloenzymes from different environments or with different cellular roles. We hope that in the future, the versatile sampling possibilities offered by IR spectroscopy will bridge key divides between the chemical, biochemical, and structural biology communities in mechanistic enzymology.

\section{Acknowledgements}

Research was supported by: European Research Council (EnergyBioCatalysis-ERC-2010-StG258600); Engineering and Physical Sciences Research Council IB Catalyst award EP/N013514/1; Biotechnology and Biological Sciences Research Council (BB/L009722/1 and BB/N006321/1). KAV and PAA are currently supported by BBSRC grant BB/R018413/1. SETK-P is funded by EPSRC grant EP/N509711/1. We thank Diamond Light Source for access to the MIRIAM beamline B22 (SM13879 and SM21651) that contributed to the results presented here, and Dr Stephen Carr and Mr Wangzhe Li for performing preliminary experiments to determine the diffraction quality of Hyd 1 crystals after electrochemical manipulation. We thank Prof Fraser Armstrong and Dr Rhiannon Evans for valuable discussion.

\section{Biographies}

Philip Ash is a Lecturer in Chemistry at the University of Leicester, following post-doctoral research at the University of Oxford. He was awarded his Ph.D in 2011 from Durham University.

Sophie Kendall-Price is currently a D.Phil. student in Inorganic Chemistry at the University of Oxford.

Kylie Vincent is a Professor of Inorganic Chemistry at the University of Oxford. She was awarded her Ph.D. in 2004 from the University of Melbourne. 


\section{References}

(1) Schneider, K.; Schlegel, H. G. Purification and Properties of Soluble Hydrogenase from Alcaligenes eutrophus H16. Biochim. Biophys. Acta - Enzymol. 1976, 452, 66-80.

(2) Léger, C.; Bertrand, P. Direct Electrochemistry of Redox Enzymes as a Tool for Mechanistic Studies. Chem. Rev. 2008, 108, 2379-2438.

(3) Léger, C. Chapter 8 - An Introduction to Electrochemical Methods for the Functional Analysis of Metalloproteins. In Practical Approaches to Biological Inorganic Chemistry; Crichton, R. R., Louro, R. O., Eds.; Elsevier: Oxford, 2013; pp 179-216.

(4) Fourmond, V.; Léger, C. Protein Electrochemistry: Questions and Answers. In Biophotoelectrochemistry: From Bioelectrochemistry to Biophotovoltaics; Jeuken, L. J. C., Ed.; Advances in Biochemical Engineering/Biotechnology; Springer International Publishing: Cham, 2016; pp 1-41.

(5) Cherepanov, A. V.; de Vries, S. Microsecond Freeze-Hyperquenching: Development of a New Ultrafast Micro-Mixing and Sampling Technology and Application to Enzyme Catalysis. Biochim. Biophys. Acta-Bioenerg. 2004, 1656, 1-31.

(6) Mitic, S.; de Vries, S. 1.22 Rapid Mixing Techniques for the Study of Enzyme Catalysis. In Comprehensive Biophysics; Egelman, E. H., Ed.; Elsevier: Amsterdam, 2012; pp 514-532.

(7) Mitić, S.; Strampraad, M. J. F.; Hagen, W. R.; Vries, S. de. Microsecond Time-Scale Kinetics of Transient Biochemical Reactions. PLOS ONE 2017, 12, e0185888.

(8) Radu, I.; Schleeger, M.; Bolwien, C.; Heberle, J. Time-Resolved Methods in Biophysics. 10. Time-Resolved FT-IR Difference Spectroscopy and the Application to Membrane Proteins. Photochem. Photobiol. Sci. 2009, 8, 1517-1528. 
(9) Lukacs, A.; Zhao, R.-K.; Haigney, A.; Brust, R.; Greetham, G. M.; Towrie, M.; Tonge, P. J.; Meech, S. R. Excited State Structure and Dynamics of the Neutral and Anionic Flavin Radical Revealed by Ultrafast Transient Mid-IR to Visible Spectroscopy. J. Phys. Chem. B 2012, 116, $5810-5818$.

(10) Kottke, T.; Lórenz-Fonfría, V. A.; Heberle, J. The Grateful Infrared: Sequential Protein Structural Changes Resolved by Infrared Difference Spectroscopy. J. Phys. Chem. B 2017, 121, $335-350$.

(11) Armstrong, F. A.; Evans, R. M.; Hexter, S. V.; Murphy, B. J.; Roessler, M. M.; Wulff, P. Guiding Principles of Hydrogenase Catalysis Instigated and Clarified by Protein Film Electrochemistry. Acc. Chem. Res. 2016, 49, 884-892.

(12) Ash, P. A.; Vincent, K. A. Spectroscopic Analysis of Immobilised Redox Enzymes under Direct Electrochemical Control. Chem. Commun. 2012, 48, 1400-1409.

(13) Ash, P. A.; Reeve, H. A.; Quinson, J.; Hidalgo, R.; Zhu, T.; McPherson, I. J.; Chung, M.W.; Healy, A. J.; Nayak, S.; Lonsdale, T. H.; Wehbe, K.; Kelley, C. S.; Frogley, M. D.; Cinque, G.; Vincent, K. A. Synchrotron-Based Infrared Microanalysis of Biological Redox Processes under Electrochemical Control. Anal. Chem. 2016, 88, 6666-6671.

(14) Ash, P. A.; Carr, S. B.; Reeve, H. A.; Skorupskaite, A.; Rowbotham, J. S.; Shutt, R.; Frogley, M. D.; Evans, R. M.; Cinque, G.; Armstrong, F. A.; Vincent, K. A. Generating Single Metalloprotein Crystals in Well-Defined Redox States: Electrochemical Control Combined with Infrared Imaging of a NiFe Hydrogenase Crystal. Chem. Commun. 2017, 53, 5858-5861.

(15) Greene, B. L.; Vansuch, G. E.; Chica, B. C.; Adams, M. W. W.; Dyer, R. B. Applications of Photogating and Time Resolved Spectroscopy to Mechanistic Studies of Hydrogenases. Acc. Chem. Res. 2017, 50, 2718-2726. 
(16) Bethel, R. D.; Darensbourg, M. Y. The Bioorganometallic Chemistry of Hydrogenase. In Bioorganometallic Chemistry; John Wiley \& Sons, Ltd, 2014; pp 239-272.

(17) Behnke, S. L.; Shafaat, H. S. Heterobimetallic Models of the [NiFe] Hydrogenases: A Structural and Spectroscopic Comparison. Comments Inorg. Chem. 2016, 36, 123-140.

(18) Bagley, K. A.; Duin, E. C.; Roseboom, W.; Albracht, S. P. J.; Woodruff, W. H. InfraredDetectable Group Senses Changes in Charge Density on the Nickel Center in Hydrogenase from Chromatium vinosum. Biochemistry 1995, 34, 5527-5535.

(19) Lubitz, W.; Ogata, H.; Rüdiger, O.; Reijerse, E. Hydrogenases. Chem. Rev. 2014, 114, $4081-4148$.

(20) The PyMOL Molecular Graphics System, Version 1.8.0.7 Schrödinger, LLC.

(21) Hidalgo, R.; Ash, P. A.; Healy, A. J.; Vincent, K. A. Infrared Spectroscopy During Electrocatalytic Turnover Reveals the Ni-L Active Site State During $\mathrm{H}_{2}$ Oxidation by a NiFe Hydrogenase. Angew. Chem. Int. Ed. 2015, 54, 7110-7113.

(22) Ash, P. A.; Hidalgo, R.; Vincent, K. A. Proton Transfer in the Catalytic Cycle of [NiFe] Hydrogenases: Insight from Vibrational Spectroscopy. ACS Catal. 2017, 2471-2485.

(23) Tai, H.; Nishikawa, K.; Suzuki, M.; Higuchi, Y.; Hirota, S. Control of the Transition between Ni-C and Ni-SIa States by the Redox State of the Proximal Fe-S Cluster in the Catalytic Cycle of [NiFe] Hydrogenase. Angew. Chem. Int. Ed. 2014, 53, 13817-13820.

(24) Greene, B. L.; Wu, C.-H.; McTernan, P. M.; Adams, M. W. W.; Dyer, R. B. ProtonCoupled Electron Transfer Dynamics in the Catalytic Mechanism of a [NiFe]-Hydrogenase. $J$. Am. Chem. Soc. 2015, 137, 4558-4566. 
(25) Greene, B. L.; Wu, C.-H.; Vansuch, G. E.; Adams, M. W. W.; Dyer, R. B. Proton Inventory and Dynamics in the $\mathrm{Ni}_{\mathrm{a}}-\mathrm{S}$ to $\mathrm{Ni}_{\mathrm{a}}-\mathrm{C}$ Transition of a $[\mathrm{NiFe}]$ Hydrogenase. Biochemistry $2016,55,1813-1825$.

(26) Dutta, A.; DuBois, D. L.; Roberts, J. A. S.; Shaw, W. J. Amino Acid Modified Ni Catalyst Exhibits Reversible $\mathrm{H}_{2}$ Oxidation/production over a Broad pH Range at Elevated Temperatures. Proc. Natl. Acad. Sci. 2014, 111, 16286-16291.

(27) Priyadarshani, N.; Dutta, A.; Ginovska, B.; Buchko, G. W.; O’Hagan, M.; Raugei, S.; Shaw, W. J. Achieving Reversible H2/H+ Interconversion at Room Temperature with EnzymeInspired Molecular Complexes: A Mechanistic Study. ACS Catal. 2016, 6, 6037-6049.

(28) Boralugodage, N. P.; Arachchige, R. J.; Dutta, A.; Buchko, G. W.; Shaw, W. J. Evaluating the Role of Acidic, Basic, and Polar Amino Acids and Dipeptides on a Molecular Electrocatalyst for $\mathrm{H}_{2}$ Oxidation. Catal. Sci. Technol. 2017, 7, 1108-1121.

(29) Dementin, S.; Burlat, B.; Lacey, A. L. D.; Pardo, A.; Adryanczyk-Perrier, G.; Guigliarelli, B.; Fernandez, V. M.; Rousset, M. A Glutamate Is the Essential Proton Transfer Gate during the Catalytic Cycle of the [NiFe] Hydrogenase. J. Biol. Chem. 2004, 279, 1050810513.

(30) Fontecilla-Camps, J. C.; Volbeda, A.; Cavazza, C.; Nicolet, Y. Structure/Function Relationships of [NiFe]- and [FeFe]-Hydrogenases. Chem. Rev. 2007, 107, 4273-4303.

(31) Szőri-Dorogházi, E.; Maróti, G.; Szőri, M.; Nyilasi, A.; Rákhely, G.; Kovács, K. L. Analyses of the Large Subunit Histidine-Rich Motif Expose an Alternative Proton Transfer Pathway in [NiFe] Hydrogenases. PLOS ONE 2012, 7, e34666.

(32) Sumner, I.; Voth, G. A. Proton Transport Pathways in [NiFe]-Hydrogenase. J. Phys. Chem. B 2012, 116, 2917-2926. 
(33) Adamson, H.; Robinson, M.; Wright, J. J.; Flanagan, L. A.; Walton, J.; Elton, D.; Gavaghan, D. J.; Bond, A. M.; Roessler, M. M.; Parkin, A. Retuning the Catalytic Bias and Overpotential of a [NiFe]-Hydrogenase via a Single Amino Acid Exchange at the Electron Entry/Exit Site. J. Am. Chem. Soc. 2017, 139, 10677-10686.

(34) Evans, R. M.; Brooke, E. J.; Wehlin, S. A. M.; Nomerotskaia, E.; Sargent, F.; Carr, S. B.; Phillips, S. E. V.; Armstrong, F. A. Mechanism of Hydrogen Activation by [NiFe] Hydrogenases. Nat. Chem. Biol. 2016, 12, 46-50.

(35) Evans, R. M.; Ash, P. A.; Beaton, S. E.; Brooke, E. J.; Vincent, K. A.; Carr, S. B.; Armstrong, F. A. Mechanistic Exploitation of a Self-Repairing, Blocked Proton Transfer Pathway in an O2-Tolerant [NiFe]-Hydrogenase. J. Am. Chem. Soc. 2018, 140, 10208-10220.

(36) Brooke, E. J.; Evans, R. M.; Islam, S. T. A.; Roberts, G. M.; Wehlin, S. A. M.; Carr, S. B.; Phillips, S. E. V.; Armstrong, F. A. Importance of the Active Site "Canopy" Residues in an $\mathrm{O}_{2}$-Tolerant [NiFe]-Hydrogenase. Biochemistry 2017, 56, 132-142.

(37) Volbeda, A.; Darnault, C.; Parkin, A.; Sargent, F.; Armstrong, F. A.; Fontecilla-Camps, J. C. Crystal Structure of the $\mathrm{O}_{2}$-Tolerant Membrane-Bound Hydrogenase 1 from Escherichia coli in Complex with Its Cognate Cytochrome B. Structure 2013, 21, 184-190.

(38) del Barrio, M.; Sensi, M.; Orain, C.; Baffert, C.; Dementin, S.; Fourmond, V.; Léger, C. Electrochemical Investigations of Hydrogenases and Other Enzymes That Produce and Use Solar Fuels. Acc. Chem. Res. 2018, 51, 769-777.

(39) Flanagan, L. A.; Parkin, A. Electrochemical Insights into the Mechanism of NiFe Membrane-Bound Hydrogenases. Biochem. Soc. Trans. 2016, 44, 315-328. 
(40) Ash, P. A.; Hidalgo, R.; Vincent, K. A. Protein Film Infrared Electrochemistry Demonstrated for Study of $\mathrm{H}_{2}$ Oxidation by a [NiFe] Hydrogenase. J. Vis. Exp. 2017, 130, e55858-e55858.

(41) Quinson, J.; Hidalgo, R.; Ash, P. A.; Dillon, F.; Grobert, N.; Vincent, K. A. Comparison of Carbon Materials as Electrodes for Enzyme Electrocatalysis: Hydrogenase as a Case Study. Faraday Discuss. 2014, 172, 473-496.

(42) Murphy, B. J.; Sargent, F.; Armstrong, F. A. Transforming an Oxygen-Tolerant [NiFe] Uptake Hydrogenase into a Proficient, Reversible Hydrogen Producer. Energy Environ. Sci. $2014,7,1426-1433$.

(43) De Lacey, A. L.; Fernández, V. M.; Rousset, M.; Cammack, R. Activation and Inactivation of Hydrogenase Function and the Catalytic Cycle: Spectroelectrochemical Studies. Chem. Rev. 2007, 107, 4304-4330.

(44) Shafaat, H. S.; Rüdiger, O.; Ogata, H.; Lubitz, W. [NiFe] Hydrogenases: A Common Active Site for Hydrogen Metabolism under Diverse Conditions. Biochim. Biophys. Acta Bioenerg. 2013, 1827, 986-1002.

(45) Lukey, M. J.; Parkin, A.; Roessler, M. M.; Murphy, B. J.; Harmer, J.; Palmer, T.; Sargent, F.; Armstrong, F. A. How Escherichia coli Is Equipped to Oxidize Hydrogen under Different Redox Conditions. J. Biol. Chem. 2010, 285, 3928-3938.

(46) Tai, H.; Nishikawa, K.; Inoue, S.; Higuchi, Y.; Hirota, S. FT-IR Characterization of the Light-Induced Ni-L2 and Ni-L3 States of [NiFe] Hydrogenase from Desulfovibrio vulgaris Miyazaki F. J. Phys. Chem. B 2015, 119, 13668-13674.

(47) Tai, H.; Higuchi, Y.; Hirota, S. Comprehensive Reaction Mechanisms at and near the $\mathrm{Ni}-$ Fe Active Sites of [NiFe] Hydrogenases. Dalton Trans. 2018, 47 (13), 4408-4423. 
(48) Kampa, M.; Pandelia, M.-E.; Lubitz, W.; van Gastel, M.; Neese, F. A Metal-Metal Bond in the Light-Induced State of [NiFe] Hydrogenases with Relevance to Hydrogen Evolution. $J$. Am. Chem. Soc. 2013, 135, 3915-3925.

(49) Murphy, B. J.; Hidalgo, R.; Roessler, M. M.; Evans, R. M.; Ash, P. A.; Myers, W. K.; Vincent, K. A.; Armstrong, F. A. Discovery of Dark pH-Dependent H+ Migration in a [NiFe]Hydrogenase and Its Mechanistic Relevance: Mobilizing the Hydrido Ligand of the Ni-C Intermediate. J. Am. Chem. Soc. 2015, 137, 8484-8489.

(50) Roncaroli, F.; Bill, E.; Friedrich, B.; Lenz, O.; Lubitz, W.; Pandelia, M.-E. Cofactor Composition and Function of a $\mathrm{H}_{2}$-Sensing Regulatory Hydrogenase as Revealed by Mössbauer and EPR Spectroscopy. Chem. Sci. 2015, 6, 4495-4507.

(51) Fritsch, J.; Scheerer, P.; Frielingsdorf, S.; Kroschinsky, S.; Friedrich, B.; Lenz, O.; Spahn, C. M. T. The Crystal Structure of an Oxygen-Tolerant Hydrogenase Uncovers a Novel Iron-Sulphur Centre. Nature 2011, 479, 249-252.

(52) Schäfer, C.; Bommer, M.; Hennig, S. E.; Jeoung, J.-H.; Dobbek, H.; Lenz, O. Structure of an Actinobacterial-Type [NiFe]-Hydrogenase Reveals Insight into $\mathrm{O}_{2}$-Tolerant $\mathrm{H}_{2}$ Oxidation. Structure 2016, 24, 285-292.

(53) Volbeda, A.; Martin, L.; Cavazza, C.; Matho, M.; Faber, B. W.; Roseboom, W.; Albracht, S. P. J.; Garcin, E.; Rousset, M.; Fontecilla-Camps, J. C. Structural Differences between the Ready and Unready Oxidized States of [NiFe] Hydrogenases. J. Biol. Inorg. Chem. $2005,10,239-249$.

(54) Gebler, A.; Burgdorf, T.; Lacey, A. L. D.; Rüdiger, O.; Martinez-Arias, A.; Lenz, O.; Friedrich, B. Impact of Alterations near the [NiFe] Active Site on the Function of the $\mathrm{H}_{2}$ Sensor from Ralstonia eutropha. FEBS J. 2007, 274, 74-85. 
(55) Greene, B. L.; Vansuch, G. E.; Wu, C.-H.; Adams, M. W. W.; Dyer, R. B. Glutamate Gated Proton-Coupled Electron Transfer Activity of a [NiFe]-Hydrogenase. J. Am. Chem. Soc. 2016, 138, 13013-13021.

(56) Radu, V.; Frielingsdorf, S.; Lenz, O.; Jeuken, L. J. C. Reactivation from the Ni-B State in [NiFe] Hydrogenase of Ralstonia eutropha Is Controlled by Reduction of the Superoxidised Proximal Cluster. Chem. Commun. 2016, 52, 2632-2635.

(57) Pearson, A. R.; Stetten, D. von; Huse, N. If You Can Get a Crystal Structure, Why Bother with Anything Else? Synchrotron Radiat. News 2015, 28, 10-14.

(58) von Stetten, D.; Giraud, T.; Carpentier, P.; Sever, F.; Terrien, M.; Dobias, F.; Juers, D. H.; Flot, D.; Mueller-Dieckmann, C.; Leonard, G. A.; de Sanctis, D.; Royant, A. In Crystallo Optical Spectroscopy (icOS) as a Complementary Tool on the Macromolecular Crystallography Beamlines of the ESRF. Acta Crystallogr. D Biol. Crystallogr. 2015, 71, 15-26.

(59) Bowman, S. E. J.; Bridwell-Rabb, J.; Drennan, C. L. Metalloprotein Crystallography: More than a Structure. Acc. Chem. Res. 2016, 49, 695-702.

(60) Kwon, H.; Smith, O.; Raven, E. L.; Moody, P. C. E. Combining X-Ray and Neutron Crystallography with Spectroscopy. Acta Crystallogr. Sect. Struct. Biol. 2017, 73, 141-147.

(61) Ciaccafava, A.; Tombolelli, D.; Domnik, L.; Fesseler, J.; Jeoung, J.-H.; Dobbek, H.; Mroginski, M. A.; Zebger, I.; Hildebrandt, P. When the Inhibitor Tells More than the Substrate: The Cyanide-Bound State of a Carbon Monoxide Dehydrogenase. Chem. Sci. 2016, 7, $3162-$ 3171.

(62) Siebert, E.; Rippers, Y.; Frielingsdorf, S.; Fritsch, J.; Schmidt, A.; Kalms, J.; Katz, S.; Lenz, O.; Scheerer, P.; Paasche, L.; Pelmenschikov, V.; Kuhlmann, U.; Mroginski, M. A.; Zebger, I.; Hildebrandt, P. Resonance Raman Spectroscopic Analysis of the [NiFe] Active Site 
and the Proximal [4Fe-3S] Cluster of an $\mathrm{O}_{2}$-Tolerant Membrane-Bound Hydrogenase in the Crystalline State. J. Phys. Chem. B 2015, 119, 13785-13796.

(63) Spatzal, T.; Perez, K. A.; Einsle, O.; Howard, J. B.; Rees, D. C. Ligand Binding to the FeMo-Cofactor: Structures of CO-Bound and Reactivated Nitrogenase. Science 2014, 345, $1620-1623$.

(64) George, S. J.; Ashby, G. A.; Wharton, C. W.; Thorneley, R. N. F. Time-Resolved Binding of Carbon Monoxide to Nitrogenase Monitored by Stopped-Flow Infrared Spectroscopy. J. Am. Chem. Soc. 1997, 119, 6450-6451.

(65) Cerqueira, N. M. F. S. A.; Gonzalez, P. J.; Fernandes, P. A.; Moura, J. J. G.; Ramos, M. J. Periplasmic Nitrate Reductase and Formate Dehydrogenase: Similar Molecular Architectures with Very Different Enzymatic Activities. Acc. Chem. Res. 2015, 48, 2875-2884. 